\title{
Social, Demographic and Labour Market Related Determinants of Health in the Adult European Population
}

\author{
ÁGNES SÁNTHA
}

Sapientia Hungarian University of Transylvania, Romania

\section{Abstract}

This paper identifies the social, demographic and labour market related determinants of the state of health and assesses the magnitude of their impact within the European adult population. The research is based on a statistical analysis on the data of the European Social Survey (ESS), round 7, 2014/2015. Subjective socioeconomic situation and partnership status are being identified as the most influential social determinants of health. Results also illuminate how work-life-balance determines health. People suffering from work-life-imbalance are more likely to become ill than those with more free time and flexible working hours.

Keywords: subjective health, socioeconomic status, partnership status, migration, social determination of health, illness risk

\section{Introduction}

A large minority, 27 per cent, of Europe's total population claims to be suffering of some kind of illness, disability or mental problem to such an extent that it hampers their daily activities. The aim of this study is to identify and to assess the effect of socioeconomic, demographic and labour market related factors upon health on European adult population on newest data.

Previous studies found only socioeconomic status and gender to be unequivocal determinants for health. Socioeconomic status positively correlates with health: generally, the better financial situation, the better health (Stronks et al. 1997, Gallo \& Matthews 2003). Gender differences in health are more complex, implying women's greater morbidity and men's lower life expectancy (Case \& Paxson 2005, Rieker \& Bird 2005, Yin 2007).

Contradictory evidence have been found by different studies for partnership status (Boyle, Feng \& Fejiten 2009, Ploubidis et al. 2015) and ethnic minority membership (Davies, Basten \& Frattini 2010, Iglesias, Narandran \& Bueno 2012, Wändell, Hjörleifsdottir \& Johansson 2013).

The third group of determinants, labour market related factors, have not sufficiently 
been studied so far with respect to their impact upon health. Unemployment and illness are strongly interrelated, poor health being a determinant of unemployment, early retirement and disability pension, but also the result of these, mostly with respect to mental health (Stronks et al. 1997, Böckerman \& Ilmakunnas 2009, Lötters et al. 2013). Among employees, occupational health hazards definitely play a role in the state of health, as heavy disability mostly occurs in dangerous industries (Claussen, Dalgard $\&$ Bruusgaard 2009). However, a gap in the previous research in the field is the lack of studies on the interrelation of employment relation (employee or self-employed/entrepreneur) and health. One of the aims of this study is to give an insight into the differences among active adults according to their employment relation. Further, the influence of job satisfaction and work-life-balance are also subject to analysis.

The central research question is which of these factors influence subjective health and to what extent. Who are more likely to be healthy and who present an increased illness risk?

The admitted limitation of this study is that measuring the impact of social determinants does not say much about the mechanisms through which they operate upon health. Further, this view is intentionally neglecting biological and genetic aspects which in turn also affect health. The relationship between age and health is obvious: older people are more likely to suffer from permanent diseases. The most important social (partly biological) determinant, the population's general ageing is thus not being discussed in this paper, rather, the emphasis is being laid upon individual-level social determinants.

\section{Data and methodology}

The empirical analysis is based upon the latest round (7) of the European Social Survey, ESS, from the years 2014/2015. There were altogether 15 participating countries in the survey: Austria, Belgium, Czech Republic, Denmark, Estonia, Finland, France, Germany, Ireland, The Netherlands, Norway, Poland, Slovenia, Sweden and Switzerland. ${ }^{1}$ The analysis can by no means be fully comprehensive for the whole continent. Nevertheless, it gives a fair insight into the agency of the social determinants of health.

Countries were categorized by the type of welfare system as grouped by EspingAndersen (1990) and Ferrera (1996) as follows: liberal = 1 (Ireland), conservative = 2 (Austria, Belgium, Switzerland, Germany, France, The Netherlands), social democratic $=3$ (Denmark, Finland, Norway, Sweden), post-socialist $=4$ (Czech Republic, Estonia, Poland, Slovenia).

The number of respondents is 28.221. Descriptive statistics (crosstabs) and explanatory models (logistic regression) are being used.

Descriptive questions refer to subjective general health with the values "very good",

1 Newly, after having completed this article, data from the UK, Portugal and Spain became available. 
"good", "fair", "bad", "very bad", and to the extent of being hampered in their daily activities by any longstanding illness, disability, infirmity or mental health problem with the values "yes, a lot", "yes, to some extent" and "not at all".

However, in descriptive statistics, variables are not being controlled for. In order to answer the central research question, to identify health's determinants and to assess the magnitude of their action, the controlled effects of possible determinants need to be studied. From the explanatory models used in social statistics, the best fitting and most suitable one for assessing the impact of social variables upon health is the binary logistic regression. This model predicts the odds ratios (probabilities) of the explanatory variables' values for a dichotomous dependent variable's values.

The original question of the ESS questionnaire was formulated as follows: "Are you hampered in your daily activities in any way by any longstanding illness, or disability, infirmity or mental health problem?" State of health, the dependent variable appears in our logistic model as a dichotomous variable recoded from the original three-category variable above, that is: $1=$ is hampered (from "yes a lot" and "yes, to some extent") and 2 = is totally healthy (from "not at all").

The model contains independent, explanatory variables which - according to the literature - are believed or proven to play part in the prevalence of health-related problems. The explanatory variables and their values in the analysis are as follows:

1. Welfare system type as identified by Esping-Andersen (1990) and Ferrera (1996)

2. Gender $(1=$ male, $2=$ female $)$

3. Socioeconomic situation: $\operatorname{good}=1$, fair $=2, \mathrm{bad}=3$

In order to eliminate the economic differences in the countries included in the study, the subjective socioeconomic status rather than income expressed in moneywas used as the indicator for the person's financial status. ${ }^{2}$

4. Partnership status: $1=$ single, 2 = with partner

In this analysis, there was no justification to further differentiate the partnership status, i.e. to separate married people from cohabiting partners, although some other studies' outcome indicate that legal marital status still plays a role in health, particularly for men (Boyle et al. 2009).

5. National minority membership $1=$ member of a national minority, $2=$ member of the majority nation

6. Employment relation: $1=$ employee, $2=$ self-employed, entrepreneur, $3=$ unemployed

7. Work satisfaction: $1=$ unsatisfied, $2=$ partly satisfied, $3=$ satisfied

8. Work-life-balance: 1 = unsatisfied, 2 = partly satisfied, $3=$ satisfied.

2 Socioeconomic status has proven to better fit into the model than the highest level of education. Working with both variables would have been not only unnecessary, but also harmful due to the mutual correlation of the two aspects, as it could eventually modify the effect of further variables. Using socioeconomic status as an indicator also eliminates the inaccuracies resulting from the education system's differences. 
The reference value is in each case the smallest value of the variable. Significant odds ratios (Exp(B) values) higher than 1 indicate an increased chance for health, and lower than 1 mean lower chances for health, compared to the reference category.

Design weights and population size weights were applied.

\section{Results}

At first, we are having a look at a compact measure of the state of health, namely the simple question on the subjective health of respondents as shown in Table 1.

Table 1: Subjective general health. $\mathrm{N}=28,196$

\begin{tabular}{|l|c|}
\hline \multicolumn{1}{|c|}{ Subjective general health } & \% of respondents \\
\hline Very good & 24.5 \\
\hline Good & 44.5 \\
\hline Fair & 24.6 \\
\hline Bad & 5.3 \\
\hline Very bad & 1.1 \\
\hline Total & 100 \\
\hline
\end{tabular}

Further, general health was assessed in the survey with another, somewhat more "objective" question, too, namely whether the respondents are being hampered in their daily activities by any illness or disability. The total illness prevalence of 27.3 per cent - being hampered a lot and to some extent - is in itself an overall increase of almost 2 per cent relative to the previous data release of just two years before, 2012. The ongoing ageing of the European population is evidently playing a role in this increase.

By the welfare system type, the distribution of health is as follows (Table 2).

As seen in Table 2, the state of health slightly differs across welfare system types. The only notable difference in the rate of those hampered in their daily activities by any illness either a lot or to some extent occurs within the post-socialist welfare system. Here, a higher proportion of respondents are hampered by some illness than in other countries.

Descriptive results indicate that the welfare system type influences subjective health. In order to assess the controlled effect of the welfare system type and of other possible determinants, a binary logistic analysis was carried out. The determinants are searched

Table 2: Subjective general health. $\mathrm{N}=28,196$

\begin{tabular}{|c|c|c|c|c|}
\hline \multirow[t]{2}{*}{ Welfare system type } & \multicolumn{3}{|c|}{$\begin{array}{l}\% \text { of those being hampered in their daily activities by } \\
\text { any longstanding illness, disability, infirmity or mental } \\
\text { health problem }\end{array}$} & \multirow[t]{2}{*}{ Total } \\
\hline & A lot & To some extent & Not at all & \\
\hline Conservative & 6.5 & 20.8 & 72.7 & 100 \\
\hline Liberal & 6.5 & 19.7 & 73.8 & 100 \\
\hline Social democratic & 6.3 & 21.0 & 72.7 & 100 \\
\hline Post-socialist & 6.8 & 21.8 & 71.4 & 100 \\
\hline Total & 6.4 & 20.9 & 72.7 & 100 \\
\hline \multicolumn{5}{|c|}{ Pearson chi-square: 403.115 , Sig $=0.000$} \\
\hline
\end{tabular}


for among the following variables: the welfare regime type, gender, socioeconomic situation, partnership status, national minority or majority membership, labour market status, work satisfaction, work-life-balance.

All data introduced into the logistic regression equation is available for 14.645 persons. The reduction in the number of cases is due to the fact that in the explanatory model the missing answers are cumulated and only those cases are being considered that have valid values in all the variables. This methodological weakness thus originates in the weakness of large datasets in general, nevertheless, even so, the huge number of cases is sufficient to pursue a trustworthy analysis.

Now let us see how these parameters behave in a logistic regression model! Is health socially determined? If yes, what causes the differences in the chances for a better health and what is the magnitude of these differences? Table 3 summarizes the effects of possible social determinants.

Table 3: The determinants of the state of health (logistic regression model)

\begin{tabular}{|c|c|c|c|}
\hline \multirow[t]{2}{*}{ Explanatory variables } & \multicolumn{3}{|c|}{$\begin{array}{l}\mathbf{N}=\mathbf{1 4 , 6 4 5} \\
\text {-2 Log likelihood: } 13932,662 \\
\text { Chi-square: } 447,703, \text { df: } 10, \text { Sig: } 0,000 \\
\text { Nagelkerke R Square: } 0,045\end{array}$} \\
\hline & $\mathrm{B}$ & Sign. & $\operatorname{Exp}(\mathrm{B})$ \\
\hline \multicolumn{4}{|l|}{ Welfare system type } \\
\hline Conservative $=1$ & &, 000 & \\
\hline Liberal &, 111 & 201 & ,912 \\
\hline Social democratic & 221 & 413 & 963 \\
\hline Post-socialist &,- 335 &, 000 & ,715 \\
\hline \multicolumn{4}{|l|}{ Gender } \\
\hline Male $=1$ & &, 000 & \\
\hline Female & ,201 &, 000 & 1,223 \\
\hline \multicolumn{4}{|l|}{ Subjective socioeconomic situation } \\
\hline Good $=1$ & &, 000 & \\
\hline Fair & , 192 &, 000 & ,871 \\
\hline Bad &, 523 &, 000 & ,387 \\
\hline \multicolumn{4}{|l|}{ Partnership status } \\
\hline No partner $=1$ & &, 000 & \\
\hline With partner &,- 201 &, 001 & 1,918 \\
\hline \multicolumn{4}{|l|}{ National minority membership } \\
\hline Member of a national minority $=1$ & &, 557 & \\
\hline Member of the majority nation &, 176 &, 071 & 1,192 \\
\hline \multicolumn{4}{|l|}{ Employment relation } \\
\hline Employee $=1$ & &, 003 & \\
\hline Self-employed, entrepreneur & , 181 &, 003 & 1,399 \\
\hline Unemployed &, 101 &, 013 & 1,110 \\
\hline \multicolumn{4}{|l|}{ Work satisfaction } \\
\hline Unsatisfied = 1 & &, 120 & \\
\hline \multicolumn{4}{|l|}{ Partly satisfied with work } \\
\hline Satisfied with work &,- 294 & ,223 & ,745 \\
\hline \multicolumn{4}{|l|}{ Satisfaction with work-life-balance } \\
\hline Unsatisfied with work-life-balance $=1$ & &, 000 & \\
\hline \multicolumn{4}{|l|}{ Partly satisfied with work-life-balance } \\
\hline Satisfied with work-life-balance &,- 143 &, 003 & 1,267 \\
\hline (constant) & $-1,444$ &, 000 &, 236 \\
\hline
\end{tabular}


In the logistic regression model the cumulated explaining power is - seen altogether - significant (see the significance of the chi-square test).

The welfare system type has a strong and significant effect even when controlled for. Compared to the citizens of countries with a conservative welfare system (in our case, Austria, Belgium, Switzerland, Germany, France, The Netherlands), the citizen of an Eastern European, post-socialist country has less chance for belonging to the group of healthy people: the odds ratio $(\operatorname{Exp}(\mathrm{B}))$ is 0,715 . This indicates that people in post-socialist countries only have slightly more than two third of the chances of a Western European to be healthy. No difference was shown between countries of the other welfare systems.

If all other variables are being controlled for, women, compared to men, are $20 \%$ more likely to be healthy $(\operatorname{Exp}(\mathrm{B})=1.223)$.

Within the same socioeconomic stratum and among people of same sex, the odds ratio for being healthy is nearly twice $(\operatorname{Exp}(\mathrm{B})=1.918)$ as high for coupled people than for singles, whether men or women, unmarried, married, separated or widowed. The correlation between partnership status and health is very strong and it does not disappear when controlled for the other variables.

The most powerful determinant of health is the perceived socioeconomic status of the individual. Table 1 shows that compared to those respondents who face no real financial problems and consider their situation as good, even those in a "fair" financial situation are more likely to get ill. Nevertheless, the odds ratio differences are striking in case of respondents of poor financial situation, as their chance for health is only one third $(\operatorname{Exp}(B)=0,387)$ of that of well-to-do people.

According to the results of the logistic regression model, being a member of an ethnic minority group does not reduce, nor does it improve health-related quality of life (the $\operatorname{Exp}(B)$ values are not significant).

Nor is unemployment a good predictor for the state of health, at least not in this model for the whole of Europe. Self-employed and entrepreneurs have higher chances for belonging to the group of healthy people than do employees $(\operatorname{Exp}(B)=1,399)$.

Work satisfaction does not enhance health, but work-life-balance does. Respondents who are satisfied with the balance between their work and private life (and have more time for themselves) have by one fifth $(\operatorname{Exp}(B)=1.267)$ higher chance for being healthy compared to those working in standard working hours.

\section{Discussion}

The logistic regression model assesses the influence of social, demographic and some labour market characteristics on the chances for better health. At first sight it strikes that the living standards of a country have in themselves, independently from all other aspects, an effect upon its citizens' health, and the relationship is positive: the higher living standards ensure a bigger chance for a healthy life. This is no surprise considering 
that life expectancy at birth and at further ages remains lower in Eastern Europe compared to Western countries. At this point it needs to be mentioned that until the date of this study, there have been no data of this round of ESS from Mediterranean countries, which as a result do not figure in the analysis. However, in previous rounds, these countries used to score higher in health-related quality of life than did all other welfare system types.

The results on socioeconomic status need not much argument, since these have been unequivocally identified by previous research. In the present study, we measured socioeconomic status by the subjective judgement on the household income with the values "good", "fair" and "bad", the best situation being the reference category. Compared to the good situation, the odds ratio for "fair" socioeconomic status is 0,871 , whereas for the "bad" situation, it is 0,387 , both results being significant. That means, poor people live with by two-third more illness risk than wealthy people with the same social and demographic features. Poor financial situation reflects a situation of multiple deprivation that reveals itself even in subjective health. Gallo \& Matthews (2003) identified socioeconomic situation as being a predictor for physical health with the contribution of negative emotions. Low socioeconomic status first impacts mental health and ends up deteriorating physical health, too.

As far as gender is concerned, it is most probably due to the higher health-related professional risks of men and to their lower health consciousness that their odds ratio for health is significantly lower than that of women. Although female morbidity is higher according to objective measures (Case \& Paxson 2005, Rieker \& Bird 2005), and even subjective rating of health is worse according to some research outcomes (Yin 2007), in this analysis, the subjective perceptions of health do not reveal this difference: on the contrary, when all other determinants are controlled for, gender makes a difference of the reverse direction, women having significantly higher health chances than men.

The second strongest interrelation is between partnership status and health. Independently from age, financial status, welfare services (welfare system type), labour market status, i.e. from all variables included in the logistic regression, singlehood negatively influences health. Some scholars argue that cohabiting unions have the same health outcomes as formal marriages for both genders (Ploubidis et al. 2015), whereas others have recently found that in our days marital status is still significant: among partnered men, those married are healthier than those cohabiting (Boyle et al. 2009). The present study did not differentiate between married and cohabiting categories, only between singles and people in a relationship of any kind. Our results support the findings of previous studies that found partnership good for health in general (Hradil 1995; Boyle et al. 2009). This beneficial effect increases with age, so that partnership status over the life course has a cumulative effect on health indicators in midlife (Ploubidis et al. 2015).

Singles suffer more often from a constant health-related problem (Boyle et al. 2009), are more disposed for loneliness and depression and more frequently ill than married 
people, more of them report about inner discomfort, sleeping problems and appetite loss (Hradil 1995); single men are facing more psychological problems than coupled men. A Chicago-based study showed that by the same amount of stress, married people are more protected from outer threats and problems than singles (Gelles 1995). Certainly, the quality of marriage is decisive, as the protective effect of a bad marriage is less than that of singleness (Gelles 1995).

The correlation between partnership status and health is beyond doubt. However, the direction of this causal relation is two-way. One of the competing approaches can be traced back to Émile Durkheim's classical sociological heritage. He considered marriage as a protective agent of health. From his work sociology knows that single and divorced men are unhappier than their married fellows, what reports for the higher prevalence of suicide among them (Durkheim 2002). The 'protection coefficient' of marriage has been assessed for men, not for women (Boyle et al. 2009). According to the anomy thesis of Émile Durkheim, the protection coefficient of marriage is higher for men than for women, so that divorce leads more often to male suicide, whereas women rather experience a feeling of liberation from bonds which they would not need anyway (Durkheim 2002). The other theory reckons with the fact of social selection. The ,selection hypothesis", as well as the empirical evidence supporting it suggests that it is not the high 'protection coefficient' of marriage at at stake. But the fact that healthy and satisfied people are more likely to find a partner (Stroebe and Stroebe 1991), while health risks reduce the marriage chances of those young people who are predisposed for illness and disability (Goldman, Takahashi \& Hu 1995, 239).

Most debate and contradiction in the literature was raised by migration. Previous research in the field indicated that migrants are healthier than the indigenous population, due to the so-called healthy migrant effect (Davies et al. 2010). However, evidence was also found for the contrary: with the ongoing process of acculturation, migrants lose the advantage they had upon arrival into the host country, further, their health is often worse than that of the native population (Wändell et al. 2013). In some countries - Estonia, Letland, Austria - the health of migrants born outside the European Union is worse, in others - Malta, the Czech Republic and Portugal - it is better than the health of locals (European Commission 2011).

From the contradictory results of international research it can be generalized that the initial advantage of the 'healthy migrants' fades with time. ${ }^{3}$ It seems that upon arrival into the receiving country a selection effect indeed works and the strong young immigrants have better health than the native local population. Nevertheless, this difference diminishes with the time spent in their new home country, and in many cases, it turns into the opposite. Worse health for ethnic minorities is particularly striking for acculturated second generational immigrants (Gordon-Larsen et al. 2003). Health sci-

3 The lack of sure, unambiguous relationships is partly due to the fact that many migrants do not feature in the official statistics, for instance in censuses or national surveys using big data. 
ence literature reports on higher rates of cardiovascular diseases in some migrant groups, as well as on the increased risk for obesity and diabetes (Davies et al. 2010: 11). Immigrant Turkish women, for instance, suffer more often from type II diabetes than the native Western Europeans, which is a result of their low labor market participation, lower education level and higher prevalence of obesity - this, in turn, signals the lack of acculturation of these migrant women (Wändell et al. 2003). There is no evidence of such health disadvantage for Turkish men who are more integrated into the receiving society than women.

Newest research considers the integration policy of receiving countries, too. Although very reliable research results have not yet been obtained, for this would require expensive and time-consuming comparative panel studies, results indicate that the migrants' state of health might develop into quite different directions according to the integration policy of the receiving country (Malmusi 2014).

The results of the logistic regression model show the independence of ethnic minority membership and health. As the analysis does not include all European countries, the independence of health status from ethnic minority membership should be dealt with carefully and suspiciously. Further, a fair differentiation between first and second generational migrants and indigenous ethnic minorities should be introduced. In many post-socialist countries ethnic minority membership carries the potential of serious conflicts and bad emotions, even if not manifested in actual crisis, which in turn worsens at least mental health. Ethnic minority membership and its potentially negative effect upon health should be submitted to further analysis at least in these conflictual multiethnic areas.

After having discussed the most important social and demographic features, let us now turn to the work-related factors that might influence the state of health. Among these, labour market status (employment, unemployment and inactivity) is thoroughly discussed in the literature. It is known that on individual level, unemployment correlates with financial status which in itself predicts higher illness risks for the poor. Unemployment also effects health behaviour and works negatively upon the state of health. Research results on breast cancer mortality suggest that unemployment correlates positively with breast cancer mortality. However, when controlling for public sector health expenditure, the original positive association between unemployment and breast cancer mortality is removed. This means, the mechanism through which correlation works is the reduced health care spending in times of unemployment (Maruthappu et al. 2014).

As far as the active working population is concerned, work impacts health through the physical conditions in the workplace, through the demanding nature of work activities and control over one's tasks, and through the contractual nature of jobs (e.g. precariousness). Job insecurity can also have an adverse effect on health. One rotating module of the ESS program - unfortunately not a part of round 7 - contains detailed information regarding working conditions and job features, which can be the subject of further analysis. For the present, the results of the logistic regression analysis indicate 
no higher illness risk for the unemployed than for employees. ${ }^{4}$ However, the chances for a healthier life are partly explained by employment relation, as self-employed and entrepreneurs are more likely to be healthy than employees, if all other variables are being controlled for. This might be due to the flexibility and personal autonomy of this status, which enhance health and quality of life. ${ }^{5}$

Although previous research on the topic was scarce, job satisfaction was expected to increase health-related quality of life. In previous studies, job satisfaction was most strongly associated with mental health; strongest relationships were found for burnout, self-esteem, depression and anxiety, whereas the correlation with subjective physical illness was more modest (Faragher, Cass \& Cooper 2005).

Our results show, however, that for the entire European adult population, chances for subjective general health cannot be predicted on the basis of work satisfaction. It is rather work-life-balance that determines health. Work-life-balance is being mostly discussed with respect to fertility and family formation and flexible, nonstandard work arrangements are being identified as instinctives to childbearing. Family-friendliness is becoming an increasingly important expectation from jobs, which includes flexible working hours and home-based work.

International research on the role of work-life-balance in health mainly focuses on the health professionals' case (Schluter et al. 2011). Burnout due to the imbalance between professional and private life is more frequent among health professionals than in the average population (Shanafelt et al. 2012), and professional surfeit often leads to physical problems.

The novelty of this study is revealing that work-life-balance has a positive influence on subjective general health in the working age European population.

\section{Summary}

This study deals with the state of health of European population, based on data from the latest round of the European Social Survey and it assesses the strong social character of health status. Some results echo the conclusions of previous studies in the sociology of health, others bring unexpected results or settle between contradictory outcomes of previous studies in the field. The novelty of this study is that it identifies the social el-

4 This is most probably due to the strong interrelation of unemployment and socioeconomic status: when controlled for socioeconomic status, the effect of unemployment disappears. Put more simply, the socioeconomic status already contains the effect of unemployment, too.

5 In Eastern Europe the attractiveness of self-employed status is rather low, only a minority of some 5\% of young people do wish for it (Váradi 2007: 28). 
ements that are in charge for the differences in the population's health state, but also assesses their magnitude, that is, the odds ratios for health of different social categories when all other possible effects are being controlled for.

On the whole, it can be stated that on the higher stairs of social hierarchy the chance for health is also higher. Persisting social inequalities remain decisive for health-related quality of life.

The most important achievement of the analysis is assessing the significantly positive effect of partnership status and work-related features: being coupled influences directly and in itself the state of health in a positive way, independently of all other social effects. Singles' hazard ratio for illness is in all social categories almost twice as high as that of coupled adults.

Employment relation impacts upon health so that self-employed and entrepreneurs are more likely to be healthy than employees of similar socioeconomic and demographic profile. Workload also has its negative effect upon health. People suffering from work-life-imbalance are more likely to become ill than those with more free time and flexible working hours.

\section{Literature}

Böckerman, P \& Ilmakunnas, P (2009). Unemployment and self-assessed health: evidence from panel data. Health Economics 18 (2), 161-179. https://doi.org/10.1002/hec.1361

Boyle, P, Feng, Z \& Feijten, P (2009). Marriage is not all it's cracked up to be: living with others, not marriage, is good for men's health. Paper presented at the Solo Living Seminar, University of Edinburgh, Edinburgh, 26 October.

Case, A \& Paxson, Christina (2005). Sex differences in morbidity and mortality. Demography 42(2), 189-214. https://doi.org/10.1353/dem.2005.0011

Claussen, B, Dalgard, OS \& Bruusgaard, D (2009). Disability pensioning: Can ethnic divides be explained by occupation, income, mental distress, or health? Scandinavian Journal of Public Health 37(4), 395-400. https://doi.org/10.1177/1403494809104220

Davies, AA, Basten, A \& Frattini, C (2010). Migration: A social determinant of migrants' health. Eurohealth 16(1), 10-12.

Durkheim, É. (2002). Suicide. New York: Routledge. https://doi.org/10.1522/cla.due.sui2

European Commission (2011). Indicators of Immigrant Integration - A Pilot Study. Eurostat Methodologies \& Working Papers. Luxembourg: Publications Office of the European Union.

Esping-Andersen, G (1990). The Three Worlds of Welfare Capitalism. Cambridge: Polity Press.

Faragher, EB, Cass, M \& Cooper, CL (2005). The relationship between job satisfaction and health: a meta-analysis. Occupational and Environmental Medicine 62, 105-112. https://doi.org/10.1136/oem.2002.006734

Ferrera, M (1996). The Southern model of welfare in Social Europe. Journal of European Social Policy 1(6), 17-37. https://doi.org/10.1177/095892879600600102

Gallo, LC, Matthews, KA (2003). Understanding the association between socioeconomic status and physical health: Do negative emotions play a role? Psychological Bulletin 129(1), 10-51. https://doi.org/10.1037/0033-2909.129.1.10 
Gelles, RJ (1995). Contemporary Families: A Sociological View. Newbury Park, California: Sage Publications.

Goldman, N, Takahashi, S \& Hu, Y (1995). Mortality among Japanese singles: A re-investigation. Population Studies 49(2), 227-239. https://doi.org/10.1080/0032472031000148486

Hradil, S (1995). Die Single-Gesellschaft [The Society of Singles]. München: C.H. Beck.

Iglesias, S., Narandran, A \& Bueno, R (2012). $1^{\text {st }}$ Research Exchange Workshop on Social Determinants of Migrants' Health Across Asia and Europe. Proceedings. Asia-Europe Foundation/Casa Asia. Barcelona, 7-9 March 2012. ASAF, Singapore

Lötters, F, Carlier, B, Bakker, B, Borgers, N, Schuring, M, Burdorf, A. (2013). The influence of perceived health on labour participation among long-term unemployed. Journal of Occupational Rehabilitation 23 (2), 300-308. https://doi.org/10.1007/s10926-012-9398-5

Malmusi, D (2014). Immigrants' health and health inequality by type of integration policies in European countries. European Journal of Public Health 25(2), 293-299.

https://doi.org/10.1093/eurpub/cku156

Maruthappu, M, Watkins, JA, Waqar, M, Williams, C, Ali R, Atun, R, Faiz, O, \& Zeltner, T (2014). Unemployment, public-sector health-care spending and breast cancer mortality in the European Union: 1990-2009. European Journal of Public Health 25(2), 330-335. https://doi.org/10.1093/eurpub/cku167

McKee, RF, Song, Z, Wanberg CR \& Kinicki AJ (2005). Psychological and physical well-being during unemployment: A meta-analytic study. Journal of Applied Psychology 90(1): 53-76. https://doi.org/10.1037/0021-9010.90.1.53

Meslé, F. (2001). Halandóság Kelet- és Nyugat-Európában: növekvő különbségek [Mortality in Eastern and Western Europe: Increasing Differences]. Regio (1), 163-172.

Ploubidis, GB, Silverwood, RJ, DeStavola, B \& Grundy, E (2015). Life-course partnership status and biomarkers in midlife: Evidence from the 1958 British birth cohort. American Journal of Public Health 105(8), 1596-1603. https://doi.org/10.2105/AJPH.2015.302644

Rieker, PP, Bird, CE (2005). Rethinking gender differences in health: why we need to integrate social and biological perspectives. The Journals of Gerontology Series B: Psychological Sciences and Social Sciences 60(2), 40-47. https://doi.org/10.1093/geronb/60.Special_Issue_2.S40

Shanafelt, TD, Boone, S \& Tan, L (2012). Burnout and satisfaction with work-life balance among US physicians relative to the general US population. Archives of Internal Medicine 172 (18), 1377-1385. https://doi.org/10.1001/archinternmed.2012.3199

Schluter, PJ, Turner, C, Huntington, AD, Bain, CJ, \& McClure, RJ (2011).Work/life balance and health: the Nurses and Midwives e-cohort study. International Nursing Review 58 (1), 28-36.

Stroebe, M \& Stroebe, W (1991). Partnerschaft, Familie und Wohlbefinden [Partnership, Family and Well-being]. In Abele, A. \& Becker, P. (Eds.) Wohlbefinden [Well-being]. Weinhein München: Juventa, pp. 155-174.

Stronks, K, Van de Mheen, H, Van den Bos, J \& Mackenbach, JP (1997). The Interrelationship between income, health and employment status. International Journal of Epidemiology 26(3), 592-600. https://doi.org/10.1093/ije/26.3.592

Tijdens, KG (2002). Gender roles and labor use strategies: Women's part-time work in the European Union. Feminist Economics 8(1), 71-99. https://doi.org/10.1080/13545700210126553

Váradi, R (2007). A fiatalok munkaeröpiaci helyzete [Labour Market Status of Young People]. Budapest: $\mathrm{KSH}$.

Wändell, PE, Hjörleifsdottir SK \& Johansson, SE (2013). Diabetes mellitus in Turkish immigrants in Sweden. Diabetes Metab 29 (4). 435-439. https://doi.org/10.1016/S1262-3636(07)70057-5

Yin, Sandra (2007). Gender disparities in health and mortality. Population Research Bureau Articles http://www.prb.org/Publications/Articles/2007/genderdisparities.aspx, accessed on 12 December 2016. 